\title{
Os itinerários terapêuticos pelo Sistema Único de Saúde (SUS) de homens trans em busca do processo transexualizador
}

\author{
Therapeutic itineraries by the Unified Health System (SUS) of trans men in search of the \\ transsexualizing process \\ Itinerarios terapéuticos por el Sistema Único de Salud (SUS) de hombres trans en busca \\ del proceso transexualizador
}

Paula Hayasi Pinho ${ }^{1 *}$, Helena Moraes Cortes ${ }^{1}$, Lorena Moura Pontes Araujo ${ }^{1}$, Marcos Venicius Gomes de Sá1, Luciana Mattos Barros Oliveira².

\section{RESUMO}

Objetivo: Analisar o itinerário terapêutico percorrido por homens transgêneros ao processo transexualizador pelo Sistema Único de Saúde (SUS) ofertado num serviço de cuidado a pessoas trans no nordeste brasileiro. Métodos: Estudo qualitativo, do tipo estudo de caso, realizado a partir de entrevistas semiestruturadas com doze homens trans que acessaram o processo transexualizador. O estudo foi aprovado por Comitês de Ética em Pesquisa. Resultados: Dos itinerários terapêuticos narrados, emergiram as categorias empíricas: a construção da identidade de gênero de homens trans; a apropriação do universo da transgeneridade; e o acesso ao Processo Transexualizador propriamente dito. O autorreconhecimento, a construção da identidade de gênero e a rede de apoio de pessoas trans precederam a busca pelos serviços de saúde e o acesso ao processo transexualizador. Serviços privados, públicos e a auto-hormonização com auxílio da internet, fizeram parte dos itinerários terapêuticos dos entrevistados, permeados pelo tempo de espera. Conclusão: Sugerese uma reestruturação na micropolítica dos serviços, para minimizar a espera para o acesso ao processo transexualizador no Sistema Único de Saúde, visando, também, extinguir barreiras que cerceiam e ferem a autonomia de pessoas trans.

Palavras-chave: Pessoas transgênero, Serviços de saúde para pessoas transgênero, Acesso aos serviços de saúde, Sistema Único de Saúde.

\begin{abstract}
Objective: To analyze the therapeutic itinerary followed by transgender men in the transsexualizing process by the Sistema Único de Saúde (SUS) offered in a care service for trans people in northeastern Brazil. Methods: Qualitative study, of the case study type, based on semi-structured interviews with tweve transgender men who accessed the transsexualizing process. The study was approved by the Research Ethics Committee. Results: From the narrated therapeutic itineraries, the empirical categories emerged: the construction of the gender identity of trans men; the appropriation of the transgender universe; and access to the Transsexualizing Process itself. Self-recognition, the construction of gender identity and the support network of trans people preceded the search for health services and access to the transsexualizing process. Private and public services and self-hormonization with the help of the internet were part of the interviewees' therapeutic itineraries, permeated by the waiting time. Conclusion: A restructuring of the micro-politics of services is suggested, in order to minimize the wait for access to the transsexualizing process in the Unified Health System, also aiming at extinguishing barriers that limit and hurt the autonomy of trans people.
\end{abstract}

Keywords: Transgender people, Health services for transgender people, Access to health services, Unifield Health System.

1 Universidade Federal do Recôncavo da Bahia (UFRB), Santo Antônio de Jesus - BA.

*E-mail: paulahpinho@gmail.com

2 Universidade Federal da Bahia (UFBA), Salvador - BA.

SUBMETIDO EM: 10/2021 


\section{RESUMEN}

Objetivo: Analizar el itinerario terapéutico que siguen los hombres transgénero en el proceso de transexualización del Sistema Único de Saúde (SUS) ofrecido en un servicio de atención a personas trans en el noreste de Brasil. Métodos: Estudio cualitativo, tipo estudio de caso, basado en entrevistas semiestructuradas con doce hombres transgénero que accedieron al proceso de transexualización. El estudio fue aprobado por el Comité de Ética en Investigación. Resultados: De los itinerarios terapéuticos narrados emergen las categorías empíricas: construcción de la identidad de género de los hombres trans; apropiación del universo transgénero; y acceso al propio Proceso de Transexualización. El autorreconocimiento, la construcción de la identidad de género y la red de apoyo a las personas trans precedieron a la búsqueda de servicios de salud y acceso al proceso de transexualización. Los servicios públicos y privados y la autohormonización con ayuda de internet formaron parte de los itinerarios terapéuticos de los entrevistados, permeados por el tiempo de espera. Conclusión: Se sugiere una reestructuración de la micropolítica de los servicios, con el fin de minimizar la espera de acceso al proceso de transexualización en el Sistema Único de Salud, buscando también extinguir barreras que limitan y dañan la autonomía de las personas trans.

Palabras clave: Personas transgénero, Servicios de salud para personas transgénero, Acceso a los servicios de salud, Sistema Único de Salud.

\section{INTRODUÇÃO}

Estudos vêm mostrando as dificuldades das pessoas transgêneras em acessar os serviços de saúde: a falta de conhecimento profissional; a demora para efetivação do atendimento; a escassez de informação; transfobia nos espaços de "cuidado"; dentre outros, acarretando na busca por serviços informais para as modificações corporais desejadas, colocando assim a própria saúde em risco (CORTES HM, et al., 2019; ROCON PC, et al., 2018).

Ademais, os obstáculos também são reais no acesso das pessoas trans aos serviços de saúde em outros países como México, Colômbia, Irlanda, Reino Unido e Estados Unidos, que nesse último caso, confirma a discriminação racial como sendo potencializador da discriminação e inviabilização do acesso (MCCANN E e SHAREK D, 2016; KEVAN W, et al., 2016; HERNÁNDEZ-VALLES J e ARREDONDO-LÓPEZ AA, 2020; DOMÍNGUEZ CM, et al., 2018).

Embora haja muito a ser melhorado, deve-se concelebrar as Portarias ํㅜ 1707/2008 e 2803/2013 que institui e redefine o Processo Transexualizador (PrTr) no âmbito do Sistema Único de Saúde (SUS), respectivamente, garantindo a integralidade do cuidado aos usuários, o acolhimento com humanização, o respeito ao uso do nome social e serviços como hormonização, cirurgias de redesignação sexual, acompanhamento clínico e psicológico a pessoas transgêneras (BRASIL, 2008; BRASIL, 2013).

Apesar do relativo avanço das políticas públicas para a população trans, destaca-se que no cotidiano dos serviços estas portarias nem sempre são respeitadas em sua totalidade (ROCON PC, et al., 2019). O contexto de patologização das transidentidades, de exclusão, de desrespeito e da burocratização nos equipamentos de saúde, afastam essa parcela da população destes espaços e os leva a buscarem serviços privados ou outros meios alternativos de "cuidados" (TENÓRIO LFP e PRADO MAM, 2016; CORTES HM, et al., 2020).

Objetivou-se, neste estudo, analisar o Itinerário Terapêutico (IT) de Homens Transgêneros (HTs) em busca do PrTr pelo SUS ofertado num serviço de cuidado a pessoas trans no nordeste brasileiro.

\section{MÉTODOS}

Trata-se de um estudo qualitativo, do tipo estudo de caso, que buscou analisar o contexto, as relações e as percepções sobre ITs de HTs (YIN R, 2015). Utilizou-se como caminho teórico-metodológico os ITs, a fim de compreender as trajetórias de busca, produção e gerenciamento do cuidado para a saúde; a quem e como as pessoas trans recorrem para tentarem solucionar seus problemas de saúde e quais recursos dispõe para garantir seus direitos (GERHARDT TE, et al., 2016). 
A pesquisa foi realizada com doze HTs num serviço de acolhimento e cuidado às pessoas trans, em um hospital universitário, localizado numa capital do nordeste. Os critérios de inclusão foram: se autorreconhecerem como HTs, maiores de 18 anos, cujo PrTr estivesse sendo realizado no serviço palco deste estudo. Todos os entrevistados tiveram a participação voluntária com a assinatura prévia de um Termo de Consentimento Livre e Esclarecido.

Utilizou-se para coleta de dados a entrevista semiestruturada. O trabalho de campo ocorreu entre setembro de 2019 e março de 2020. Analisou-se os dados por análise temática (MINAYO MCS, 2012). As entrevistas foram numeradas e os nomes dos entrevistados substituídos por "E" seguido pelo respectivo número da entrevista. Obedeceu aos princípios éticos da Resolução № 466/12, e foi aprovado junto ao Comitê de Ética em Pesquisa (CEP) da Universidade Federal do Recôncavo da Bahia, sob o parecer no 3.126.843/19, e junto ao CEP da Universidade Federal da Bahia, sob parecer 3.462.650/19.

\section{RESULTADOS E DISCUSSÃO}

Em relação às características sociodemográficas dos 12 participantes do estudo, a maior parte era solteiro, possuía ensino superior incompleto, tinham entre 20 e 30 anos de idade e não possuíam renda ou esta era menor que 1 salário mínimo (Tabela 1).

Tabela 1 - Caracterização sociodemográfica dos entrevistados.

\begin{tabular}{lc}
\hline Variável & $\mathbf{N}=\mathbf{1 2}$ \\
\hline Estado civil & 10 \\
\hline Solteiro & 2 \\
Casado/união estável & 8 \\
\hline Idade & 3 \\
\hline $20-30$ & 1 \\
$31-40$ & \\
$41-50$ & 1 \\
\hline Escolaridade & 1 \\
\hline Fundamental incompleto & 8 \\
Médio completo & 2 \\
Superior incompleto & \\
Superior completo & 1 \\
\hline Renda & 3 \\
\hline Não declarada & 3 \\
Não possui renda & 1 \\
Até 1 salário mínimo & 3 \\
Entre 1 e 2 salários mínimos & 1 \\
Entre 2 e 3 salários mínimos & \\
Mais de 3 salários mínimos & 3 \\
\hline Mora com & 3 \\
\hline Pais & 4 \\
Esposa & 1 \\
Somente a mãe & 1 \\
Somente o pai &
\end{tabular}

Fonte: Pinho PH, et al. 2021.

Quanto ao caminho percorrido pelos $12 \mathrm{HTs}$ em busca do PrTr no SUS, alguns entrevistados começaram seu processo de autorreconhecimento como HT por meio de mídias e redes sociais, encontrando redes de apoio ou informações sobre a mamoplastia masculinizadora no serviço privado. Com isso, muitos entrevistados começaram sua auto-hormonização, por considerarem longo o tempo de espera para acesso do PrTr no SUS e por não terem acesso aos serviços privados, sendo indicados, por estes, a procurarem serviços públicos que oferecessem o PrTr. Outros descobriram o PrTr no SUS por meio das redes sociais ou por indicação de uma rede de apoio composta por familiares, amigos ou colegas de trabalho (Figura 1). 
Figura 1 - Itinerários terapêuticos dos entrevistados.
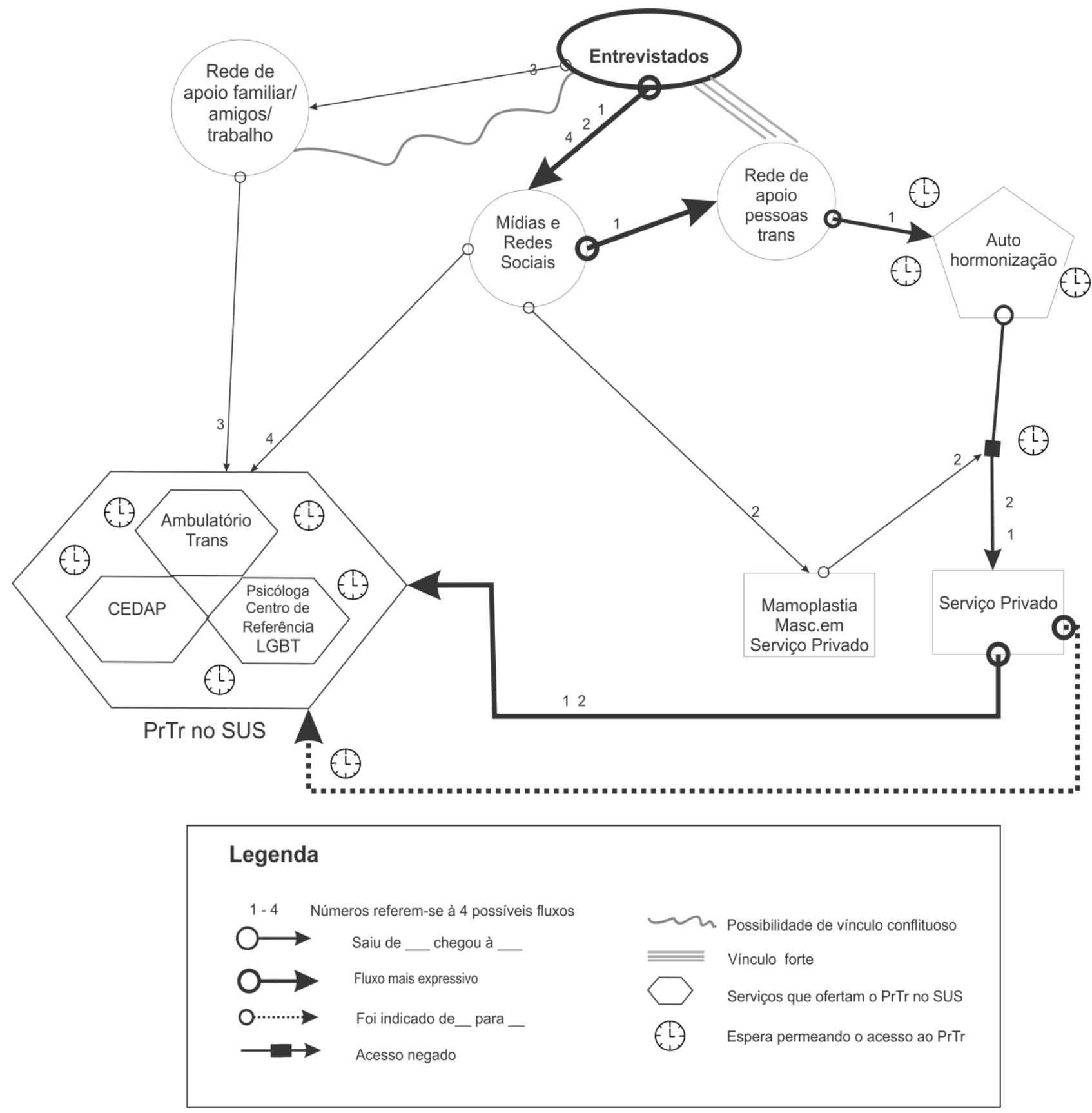

Fonte: Pinho PH, et al. 2021.

Assim, dos ITs narrados, emergiram categorias empíricas que foram organizadas em três fases, de modo a refletir a progressão dos ITs apresentados, remontando uma ordem temporal percorrida, a fim de compreender as vivências narradas por cada participante.

\section{Fase I: A construção da identidade de gênero de homens trans}

Apresenta-se, aqui, as percepções e vivências dos entrevistados sobre sua identidade masculina e sua relação com seus corpos e com a sociedade. Muitas vezes, é no período da infância que as pessoas trans percebem que não se enquadram nas "normas de gênero" (OLIVEIRA BP, 2017). Assim, observou-se nos relatos que o caminho para o processo de construção da identidade de gênero e do autorreconhecimento como HTs pareceu se iniciar nessa época, causando-lhes um sentimento de não-pertencimento aos padrões de gênero que Ihe foram impostos quando criança: 
"Quando eu era criança, gostava de brincar com brinquedos de meninos... eu usava muito a imaginação. Eu sempre gostava de fingir ser personagens e eram sempre a versão fantasiosa de você, era sempre um menino" (E11).

A cisheteronormatividade compulsória, presente no tecido social e imposta à pessoa transgênera, impedea de manifestar sua forma de ser e estar no mundo, tendendo a causar-lhe intenso sofrimento psíquico, o que demanda reconfigurar seus conceitos e conceber o enorme espectro da diversidade humana como parte integrante de si mesma (GRADE CG, et al., 2019).

Com isso, alguns entrevistados relataram dificuldade em assimilar o processo pelo qual estavam passando, desconhecendo a transgeneridade como uma possibilidade de existência causando-Ihes sentimentos de angústias e sofrimento psíquico:

"É esse sofrimento de você olhar e não se ver. É esse sofrimento diário, na verdade. O pessoal pergunta: 'Nossa, como você leva o câncer tão de boa?' E eu falo 'gente o que é um câncer para quem é transgênero? Não é nada, né?!' Tem esse sofrimento diário. Então quando você vai passar pelo câncer, se torna uma coisa muito pequena com relação ao sofrimento" (E8).

"Eu comecei a entrar em desespero pra fazer alguma coisa, pra tipo, mudar alguma coisa. Tudo parecia uma tortura, fazer tudo era uma tortura, tudo parecia o fim do mundo. Eu me vestir, tudo! Todas as minhas relações, tudo o que eu fazia... enfim... Eu era o fim do mundo" (E11).

Segundo Oliveira BP (2017), o "olhar do outro" é, em parte, responsável pelo processo de autorreconhecimento das pessoas trans, pois as instiga a pensarem sobre quem realmente são. Entretanto, devido à imposição cisheteronormativa, que rotula as identidades, esse olhar também pode ser negativo, uma vez que se torna uma referência de (des)validação da identidade de gênero (LANZ L, 2018).

Diante disso, compreende-se a necessidade de se obter fontes de encorajamento, pois revelar-se trans à sociedade pode dificultar a obtenção de redes de apoio (LANZ L, 2018). No âmbito familiar das pessoas trans, observa-se, recorrentemente, a dificuldade de se obter apoio, uma vez que gerações anteriores parecem entender a transgeneridade como uma transgressão à cisheteronormatividade (OLMO ROJAS M, 2018), como relata um participante:

"Meu irmão tem 13 anos. Na minha frente ele me trata como ele, ou quando não trata, eu não respondo e ele já nota que errou e conserta. Só que na frente dos meus pais ele não me trata como ele. Porque minha mãe falou que se ele tratar, ele apanhava" (E7).

Apesar de haver muitos conflitos familiares envolvendo as pessoas trans, quando há um bom relacionamento entre pais e filhos trans, há uma redução significativa nos relatos de sintomas de depressão e ansiedade (OLMO ROJAS M, 2018). Pessoas trans que possuem uma rede de apoio podem experimentar uma melhor saúde física e mental, maior entusiasmo em viver, além de terem a sensação de pertencimento nos diversos âmbitos sociais (COOLHART D e SHIPMAN D, 2017). Ademais, essas redes de apoio ajudam no desenvolvimento da resiliência pessoal desses homens, que se configura como a capacidade de se fortalecer internamente após passar por situações adversas, tomando as experiências ruins como aprendizado (CESAR MM, et al., 2020).

Observou-se que alguns entrevistados obtiveram incentivo no seu processo de autorreconhecimento como homens trans, de diversos segmentos sociais, como: profissionais da saúde; a família, ou parte dela; e, até mesmo, os meios de comunicação:

"Meu pai, alguns irmãos e minha tia, que é uma das pessoas que mais me apoia desde que eu comecei, desde que eu conversei com ela. E, primeiramente, minha namorada, que me apoiou desde o princípio. Alguns amigos também me apoiam [...] no meu trabalho [...], eu sou muito feliz, porque todas as pessoas me respeitam" (E9). 
"Foi aí que eu conheci alguns HTs e me identifiquei. Depois teve toda aquela repercussão da novela também, que ajudou bastante e foi quando eu realmente me assumi novamente pra minha mãe" (E10).

Esta novela foi muito importante para a visibilidade trans, pois os telespectadores, que muitas vezes desconhecem o que é a transgeneridade, puderam refletir sobre as informações problematizadas no enredo (MOREIRA J, et al., 2018).

\section{Fase II: A apropriação do universo da transgeneridade}

Após se autorreconhecerem como pessoas trans, os entrevistados passaram por processos que os ajudaram a se apropriar do universo da transgeneridade, como a representatividade social do ser HT:

"Foi através da pesquisadora trans... ela foi na minha turma e a partir do depoimento dela, entendi que existiam pessoas trans de outras formas, além do que a gente vê, pessoas trans marginalizadas... mas a partir do momento que eu entendi que pessoas trans estão em todos os lugares, eu comecei a aceitar a questão de ser HT. A partir daí eu comecei a fazer esse processo de aceitação, de no caso fazer essa transição" (E6).

Estar inserido em uma rede de apoio composta por seus pares, influencia na construção da identidade social transgênera (GRADE CG, et al., 2019), pois, além de ser uma forma para se obter suporte, possibilita o compartilhamento de experiências, sentimentos e dúvidas, de modo a facilitar o percurso da transição de gênero e aliviar a impressão de estarem sozinhos no mundo (SILVA BB e CERQUEIRA-SANTOS E, 2018).

Ao chegarem à decisão de buscarem profissionais para iniciarem o PrTr, alguns dos entrevistados foram auxiliados pelas redes de apoio formada por pessoas trans que já percorreram esses caminhos:

"Porque a gente sempre pesquisa na internet, tem grupos de apoio de vários HTs e fica um dando dica para o outro de conseguir, onde estava indo... o caminho mais fácil" (E11).

"Eu procurei ele, que ele era a figura de referência, e ai ele me colocou no Grupo 2 e a partir desse grupo do censo eu tive acesso a outros homens trans que já faziam inclusive acompanhamento aqui [...] o Grupo 2 era um grupo do Facebook que fazia o censo dos HTs pelo Brasil inteiro" (E6).

Destaca-se, inclusive, que alguns jovens trans utilizam as mídias sociais como meios de informações e preferem conteúdos sobre saúde divulgados informalmente pelas próprias pessoas trans, devido a linguagem ser de fácil compreensão (EVANS Y, et al., 2017).

Entretanto, outros HTs precisaram buscar por si só serviços que realizam o PrTr e um dos meios mais evidenciados nas narrativas como facilitadores para encontrá-los foi a internet, sendo o principal meio de pesquisa para localizar profissionais de saúde qualificados.

A internet e as mídias sociais vêm aparecendo como espaços significativos para as trajetórias da população trans (BRAZ C, 2019; PANTE AL e FERNANDES ER, 2019; SEMPOL D, et al., 2017). As redes sociais desenvolvidas na internet podem se tornar espaços de identificação com outros indivíduos, conferindo uma sensação de pertencimento e proximidade (PANTE AL e FERNANDES ER, 2019). Nesse sentido, a internet figura como espaço político de construção de identidades e de visibilidade para pessoas trans, onde possuem maior autonomia do que os meios hegemônicos de comunicação (THEODORO HGS, 2016; PANTE AL e FERNANDES ER, 2019).

\section{Fase III: $\mathrm{O}$ acesso ao Processo Transexualizador propriamente dito}

Nesta última fase, analisou-se o acesso aos cuidados em saúde pelos entrevistados. Após alguns caminhos percorridos e o entendimento das diversas possibilidades de vivências e modificações corporais 
possíveis no SUS, os HTs chegam aos serviços públicos de saúde. Percebeu-se que, mesmo após serem acolhidos num serviço de saúde destinado ao cuidado de pessoas trans, eles continuaram suas trajetórias de idas e vindas entre os serviços, entre os espaços de cuidados e as redes sociais.

Nestas idas e vindas, o tempo de espera permeou o IT dos entrevistados, destacando-se na chegada ao serviço de saúde, por impactar diretamente no início das transformações corporais desejadas.

"O tempo é uma dificuldade, demorou uns 3 meses, para marcar a primeira consulta, acho que o tempo é fator negativo" (E12).

O tempo de espera na trajetória dos entrevistados esteve presente nas filas dos serviços de saúde, e também, na expectativa do sujeito em relação ao cuidado que receberia; na luta para que direitos como o nome social sejam respeitados; na espera pela despatologização da transgeneridade; na espera para falar sobre sua identidade de gênero com amigos e familiares; na espera por compreender os fluxos do sistema de saúde e para que profissionais de saúde se sensibilizem e se (trans) qualifiquem e, sobretudo, na espera por mudanças culturais que terminem com a estigmatização e o preconceito (BRAZ C, 2019; BRAZ C, 2017; SAUER MS e SENNA A, 2016; TENÓRIO LFP e PRADO MAM, 2016). Parte da angústia causada pelo tempo de espera observa-se a seguir:

"Essa era a sexta semana que eu tentava ligar e tinha sempre algum problema, ou liguei muito tarde a primeira vez, aí [...] a menina estava de férias, na outra semana ninguém atendeu, na outra ela foi num congresso. E mesmo assim hoje liguei e finalmente consegui falar com ela e por acaso ela disse "você precisa trazer o laudo". E ainda bem que eu tinha tirado o dia pra isso, porque se não ia ser só o final de semana. Se você não consegue um dia, você tenta amanhã? Não! Você tenta daqui a uma semana! Então são dois meses só pra conseguir" (E11).

Dessa forma, a espera nos serviços de saúde acaba por reiterar as vulnerabilidades vivenciadas pelas pessoas trans, sendo que o tempo desses sujeitos parece ser considerado sem valor e estes acabam por não ter alternativas senão esperar (ORTEGA J, et al., 2017). Como resultado dessa espera, além do sofrimento gerado na vida dos entrevistados, há efeitos diretos nos itinerários, representados por um emaranhado nos caminhos em busca pelo PrTr nos serviços, visto que estes homens recorrem a atendimentos nos serviços privados ou buscam a sua auto-hormonização:

"Eu acho que é mais rápido [serviço particular]. A fila de espera do SUS é imensa. Quatro, cinco anos de espera... e eu não sei se tenho saúde pra isso. Mental, no caso. E aí eu vou trabalhar pra juntar a quantia que precisa para os médicos particulares" (E7).

"Tive dificuldade quando morava no interior, porque não tinha acompanhamento médico e eu fazia o uso dos medicamentos de forma aleatória como "dava na telha", como alguém que já vinha tomando há um tempo me indicava 'eu tomei e deu certo, toma também', aí eu tomava" (E10).

A distribuição geográfica de serviços habilitados para o PrTr no SUS não é homogênea e se configura como uma barreira de acesso, pois existe uma concentração de serviços nas capitais e uma desigualdade de distribuição nas diferentes regiões do Brasil (ROCON PC, et al., 2019). Em 2018, havia 6 unidades habilitadas para ofertar o PrTr no Sudeste e apenas uma no Nordeste, havendo um gasto financeiro no deslocamento dos usuários para as áreas de oferta do serviço e a predisposição para que pessoas transgêneras busquem formas alternativas para ter acesso às modificações corporais no mercado clandestino (ROCON PC, et al., 2019).

Um dos participantes expõe caminhos e obstáculos que levam pessoas trans à auto-hormonização, até mesmo para aqueles que residem próximo aos serviços especializados. As dificuldades ocorrem porque existe uma demanda maior que a oferta e essa falta de profissionais que prolonga o tempo de espera alia-se à ansiedade, criando gatilhos para o início da hormonização por conta própria. 
"Aqui em X [grande capital] tem uma demanda muito grande pelos serviços e pouca oferta, assim muita gente acaba ficando marcado pra dois, três meses depois e, aí as pessoas acabam buscando a clandestinidade, buscando se hormonizar por conta própria e isso é perigoso" (E6).

Entretanto, deve-se refletir sobre a auto-hormonização para além de seus riscos, como uma possibilidade de autonomia do sujeito sobre seu próprio corpo, pois este acaba sendo um caminho alternativo tomado, muitas vezes, pela escassez de serviços para atender a demanda da população, sendo a internet um dos principais meios utilizados para informações sobre como realizá-la (CAUX TR, 2018).

Há uma relação dicotômica entre os serviços privados e públicos, o que se evidencia quando os participantes E01 e E10 procuram o serviço privado e acabam tendo o atendimento negado pela inexistência de profissionais especializados, tornando o atendimento privado uma via obstruída para pessoas trans que desejam realizar modificações corporais. Em contrapartida, o SUS se estruturou para receber as pessoas trans:

"Comecei tudo pelo SUS, porque o privado ainda está atrasado" (E1).

"Eu procurei o meu plano de saúde e os profissionais falaram para mim que eles não atendiam o meu caso, porque eles não tinham especialização na área e eles próprios me encaminharam pra cá, falaram 'procura o Hospital $X$ [hospital universitário], lá tem uma equipe multidisciplinar que é um pessoal que já entende $o$ lado de vocês e vai atender vocês melhor"' (E10).

Em relação ao acompanhamento endocrinológico para pessoas trans, não basta apenas ter recursos para acessar a hormonização, pois muitas vezes os serviços privados têm dificuldades em oferecer esse atendimento (BRAZ C, 2019). A busca pela saúde integral da população trans é uma questão que afeta todas as classes sociais, pois nem sempre dispor de recursos para uso da rede privada ou ter um plano de saúde garantem o acesso (BRAZ C, 2017).

Com a ameaça de desmonte do SUS, a saúde pública tende a atuar de forma complementar à rede privada, ofertando serviços que este se desinteressa em investir por buscar atender quem tem poder aquisitivo para ter acesso ao mercado e, raramente, buscam abordagens de cuidado integral e multiprofissional (SILVA HC, 2019).

É nesse contexto de luta e resistência que são constituídos os recentes serviços públicos específicos para a população trans, que estão marcados pela escassa disponibilidade no território e a alta demanda com necessidades urgentes. Além disso, evidencia-se como a falta de capacitação dos profissionais de saúde em relação ao PrTr dificultando o entendimento das demandas de saúde da população trans, repercutindo no atendimento dos entrevistados:

"Eu queria muito usar o binder [...], então eu fui na ginecologista para conversar com ela e ninguém tinha ideia de nada, ninguém sabia me informar" (E11).

"Eu queria voltar nessa psicóloga, mas foi péssimo, ela não sabia lidar com esse tipo de coisa [transgeneridade]. Ela me pediu para fazer uma intersecção. Tipo dois círculos com intersecção. Ai as coisas que eu fazia que eram estereotipicamente de meninos e estereotipicamente de meninas e as coisas que não são nenhum dos dois, para eu, aprender a me identificar melhor com o gênero e... foi horrível! Eu fiquei muito chateado" (E11).

Seria possível avançar em relação a qualificação dos profissionais para saúde integral da população trans, por meio de reformulação das matrizes curriculares dos cursos da saúde e da educação permanente para os profissionais (SILVA LKM, et al., 2017; CORTES HM, et al., 2020). A necessidade de inclusão de temáticas como gênero e sexualidade nas matrizes curriculares dos cursos da área da saúde, aliadas à educação permanente no cotidiano dos serviços, ficaram evidentes na narrativa dos entrevistados, considerando-se a necessidade de profissionais cada vez mais (trans)competentes. 


\section{CONSIDERAÇÕES FINAIS}

Aponta-se a necessidade de uma reestruturação no modo como se dão as relações e as atividades cotidianas dos serviços, para minimizar a espera para o acesso ao processo transexualizador no Sistema Único de Saúde, visando, também, extinguir barreiras que cerceiam e ferem a autonomia de pessoas trans; bem como estabelecer mecanismos eficientes de informação a respeito dos serviços ofertados a essa população no âmbito do SUS. Considera-se premente o investimento na formação de profissionais da APS aptos a prescrever/acompanhar o uso de hormônios pelos HTs que assim o desejam, consolidando, a democratização do acesso aos serviços de saúde e a garantia da universalidade e integralidade no cuidado. Além disso, a promoção dos direitos humanos de modo a contemplar o respeito e a efetivação do uso do nome social em todos os espaços, em consonância com a inclusão de temas sobre educação sexual e de gênero nas universidades, são proposições necessárias para combater as várias formas de discriminação expressas nos itinerários desses usuários do e no SUS.

\section{REFERÊNCIAS}

1. BRASIL. Portaria ำ 1.707/2008, de 18 de agosto de 2008. Institui, no âmbito do Sistema Único de Saúde (SUS), o Processo Transexualizador, a ser implantado nas unidades federadas, respeitadas as competências das três esferas de gestão. 2008. Disponível em: https://bvsms.saude.gov.br/bvs/saudelegis/gm/2008/prt1707_18_08_2008.html. Acesso em: 12 out. 2021.

2. BRASIL. Portaria no $2.803 / 2013$, de 19 de novembro de 2013. Redefine e amplia o Processo Transexualizador no Sistema Único de Saúde (SUS). https://bvsms.saude.gov.br/bvs/saudelegis/gm/2013/prt2803_19_11_2013.html. Acesso em: 12 out. 2021.

3. BRAZ C. Transmasculinidades, salud y espera - antropología del tiempo y el acceso a la salud para hombres trans en Brasil. In: PECHENY M, PALUMBO M (Org.). Esperar y hacer esperar: escenas y experiencias en salud, dinero y amor. 1 ed. Buenos Aires: Teseo, 2017, 147-164p.

4. BRAZ C. Vidas que esperam? Itinerários do acesso a serviços de saúde para homens trans no Brasil e na Argentina. Cadernos de Saúde Pública, 2019; 35(4): 1-13.

5. CAUX TR. O hormônio traz pra realidade todos os nossos sonhos ocultos: a experiência de mulheres transexuais e travestis com o processo medicamentoso de hormonização. Dissertação (Mestrado em Medicamentos e Assistência Farmacêutica) - Programa de Pós-Graduação em Medicamentos e Assistência Farmacêutica. Universidade Federal de Minas Gerais, Belo Horizonte, 2018; 167p.

6. CESAR MM, et al. La resiliencia en jóvenes trans como factor protector de la discriminación social. In: I Congreso Virtual de Ciencias Básicas Biomédicas de Granma. Manzanillo: Cibamanz, 2020, 1-12p. Disponível em: http://www.cibamanz2020.sld.cu/index.php/cibamanz/cibamanz2020/paper/view/168/110. Acesso em: 26 out. 2021.

7. COOLHART D, SHIPMAN D. Working toward family attunement: Family therapy with transgender and gendernonconforming children and adolescents. Psychiatric Clinics of North America, 2017; 40(1): 113-125.

8. CORTES HM, et al. Vivências de mulheres transgêneras de um município do recôncavo da Bahia. Revista Eletrônica Acervo Enfermagem, 2019; 1: e1879.

9. CORTES HM, et al. O (des)acesso de pessoas transgêneras aos serviços de saúde no recôncavo baiano. Cadernos de Gênero e Diversidade, 2020; 6(4): 159-180.

10. DOMÍNGUEZ CM, et al. Acceso a servicios de salud en mujeres transgénero de la ciudad de Cali, Colombia. MedUNAB, 2018; 20(3): 296-309.

11. EVANS $\mathrm{Y}$, et al. Understanding online resource use by transgender youth and caregivers: A qualitative study. Transgender health, 2017; 2(1): 129-139.

12. GERHARDT TE, et al. Itinerários terapêuticos: integralidade no cuidado, avaliação e formação em saúde. Rio de Janeiro: CEPESC/ IMS/ UERJ - ABRASCO, 2016; 440p.

13. GRADE CG, et al. Patologização da transexualidade a partir de uma revisão integrativa. Psicologia, Saúde \& Doenças, 2019; 20(2): 435-451.

14. HAMADA RKF, et al. Conhecendo o Sistema Único de Saúde: um olhar da população. Revista de Atenção Primária à Saúde, 2018; 21(4): 504-515.

15. HERNÁNDEZ-VALLES J, ARREDONDO-LÓPEZ AA. Barreras de acceso a los servicios de salud en la comunidad transgénero y transexual. Horizonte sanitario, 2020; 19(1): 19-25.

16. KEVAN W, et al. Serving transgender people: clinical care considerations and service delivery models in transgender health. The Lancet, 2016; 388(10042): 401-411.

17. LANZ L. Por que tenho medo de lhe dizer quem sou. In: RIBEIRO PRC, et al. (Org.). Corpo, gênero e sexualidade: resistência e ocupa(ações) nos espaços de educação. Rio Grande: Editora da FURG, 2018, 49-67p. 
18. MCCANN E, SHAREK D. Mental health needs of people who identify as transgender: A review of the literature. Archives of psychiatric nursing, 2016; 30(2): 280-285.

19. MINAYO MCS. Análise qualitativa: teoria, passos e fidedignidade. Ciência \& saúde coletiva, 2012; $17(3): 621-626$.

20. MOREIRA J, et al. Visibilidade e Representatividade Transexual: A personagem Ivana em "A Força do Querer". In: $41^{\circ}$ Congresso Brasileiro de Ciências da Comunicação. Joinville: Intercom, 2018; 1-12p. Disponível em: https://portalintercom.org.br/anais/nacional2018/resumos/R13-0665-1.pdf. Acesso em: 26 out. 2021.

21. OLIVEIRA BP. "A gente não se descobre, a gente se define": as subjetividades trans* no HUB-DF. Dissertação (Mestrado em Ciências e Tecnologias em Saúde) - Programa de Pós-Graduação em Ciências e Tecnologias, Universidade de Brasília, Brasília, 2017; 203p.

22. OLMO ROJAS M. Relación entre el apoyo social percibido y los síntomas de ansiedad y depresión en población transexual/transgénero. Dissertação (Mestrado em Psicologia Geral Sanitária) - Faculdade de Ciências Humanas e Sociais, Universidad Pontificia Comillas, Madrid, 2018; 26p.

23. ORTEGA J. Otros cuerpos, otros tiempos: experiencias de espera de personas trans en el sistema público de salud. In: PECHENY M, PALUMBO M (Org.). Esperar y hacer esperar: escenas y experiencias en salud, dinero y amor. 1 ed. Buenos Aires: Teseo, 2017, 125-146p.

24. PANTE AL, FERNANDES ER. Novas demandas, novos espaços: pessoas trans e ativismos on line como estratégia de visibilidade. Rev. Dir. Cid, 2019; 11(3): 617-635.

25. PECHENY M, PALUMBO M. Esperar y hacer esperar: Escenas y experiencias en salud, dinero y amor. Buenos Aires:Teseo, 2017; 280p.

26. ROCON PC, et al. Desafios enfrentados por pessoas trans para acessar o processo transexualizador do Sistema Único de Saúde. Interface-Comunicação, Saúde, Educação, 2019; 23: 1-14.

27. ROCON PC, et al. Diversidade de gênero e Sistema Único de Saúde: uma problematização sobre o processo transexualizador. SER Social, 2018; 20(43): 432-448.

28. SAUER MS, SENNA A. Transexualidade e saúde na cidade de salvador: reflexões de duas estudantes. In: DENEGA AMO, et al. (Org.). Gênero na psicologia: saberes e práticas. 1 ed. Salvador: CRP-03, 2016, 140-156p.

29. SEMPOL D, et al. Forjando identidades Trans masculinos en un servicio de salud público uruguayo. In: BRAZ CA, HENNING CE (Org.). Gênero, sexualidade e saúde: diálogos latino-americanos. Goiânia: Editora da Imprensa Universitária, 2017, 143-171p.

30. SILVA BB, CERQUEIRA-SANTOS E. Apoio social na autoestima e identidade social de pessoas trans brasileiras. Psico, 2018; 49(4): 422-432.

31. SILVA HC. "Cata o recado, mona": condicionantes políticos, econômicos e culturais no processo transexualizador no SUS: a experiência do Hospital das Clínicas da Universidade Federal de Pernambuco. Dissertação (Mestrado em Serviço Social) - Programa De Pós-Graduação Em Serviço Social, Universidade Federal de Pernambuco, Pernambuco, 2019; 163p.

32. SILVA LKM, et al. Uso do nome social no Sistema Único de Saúde: elementos para o debate sobre a assistência prestada a travestis e transexuais. Physis: Revista de Saúde Coletiva, 2017; 27(3): 835-846.

33. TENÓRIO LFP, PRADO MAM. As contradições da patologização das identidades trans e argumentos para a mudança de paradigma. Revista Periódicus, 2016; 1(5): 41-55.

34. THEODORO HGS. Visibilidades midiáticas da transgeneridade: reflexões sobre as interfaces entre comunicação, consumo e cidadania com base em um estudo de caso das vivências de Laerte Coutinho. Temática, 2016; 12(11): 214-228.

35. YIN R. Estudo de Caso: Planejamento e métodos. 5aㅗ ed. Porto Alegre: Bookman, 2015; 320p. 